\title{
ОПТИМАЛЬНЕ ЗА ВИТРАТАМИ ПАЛИВА ПРОГРАМНЕ КЕРУВАННЯ СИСТЕМАМИ 3 ТРАНСПОРТНИМ ЗАПІЗНЮВАННЯМ
}

Питанням програмного оптимального керування присвячена досить велика кількість праць $[3,6,9,10]$, при цьому у більшості з них під оптимальним програмним керуванням мається на увазі визначення у функції часу такого керуючого впливу і відповідної до нього фразової траєкторії об'єкта, які є розв'язок заданої оптимізаційної задачі.

Найближчими до класу задач на оптимум витрат палива є задача максимальної швидкодії [5,6]. Ця близькість обумовлена низкою факторів i, зокрема, тотожним характером зміни керуючого впливу на відповідних ділянках отриманого руху системи. Виходячи із цього, візьмемо за основу методику синтезу оптимальних керуючих впливів, запропонованих в [6] для систем із максимальною швидкодією і адаптуємо її до задач на оптимум витрат палива. При цьому основними відмінними особливостями, які знаходять своє відображення у методиці побудови оптимальних за витратами палива керувань, є наступні:

1. рух системи керування з транспортним запізнюванням описуються диференціальними рівняннями із загаяним аргументом, що примушує використовувати відповідні правила їх інтегрування;

2. оптимальні за витратами палива керування відрізняються від подібних до них керувань у системах із максимальною швидкістю як числом рівнів, так й інтервалів їхньої знакосталості. Це призводить до збільшення як розмірності оптимізаційної задачі, так і до неоднорідності розв'язку рівнянь динаміки систем керування;

3. внаслідок збільшення числа рівнів та інтервалів оптимального керування зростає число шуканих параметрів, якими $є$ відповідні моменти перемикання та сталі інтегрування рівнянь динаміки систем керування. Це призводить до суттевої залежності розв'язку даної оптимізаційної задачі від додаткових умов, які випливають із принципу максимуму [2], і можуть бути визначені лише для деяких моментів перемикання. У зв'язку з цим, можливість відшукання розв'язку задачі на оптимум витрат палива залежить від порядку рівняння динаміки системи керування.

Таким чином, якщо перші два фрактори і створюють певні труднощі при аналітичному розв'язанні даної оптимізаційної задачі, то останне зауваження є принциповим, що обмежуе клас систем, для яких аналітично може бути отримане оптимальне за мінімумом витрат палива програмне керування.

${ }^{0}$ (c) К.Х. Зеленський, В.М. Ігнатенко, О.А. Стенін , 2006 
Використовуючи вказану методику, отримаємо аналітичні залежності моментів перемикання оптимального керування від вигляду критеріїв витрати палива та межових умов для одного із найпростіших класів динамічних систем із транспортним запізнюванням - систем керування другого порядку.

\section{Оптимальне програмне керування системою із двох інтегруючих ланок}

Рівняння динаміки системи керування, структура якої відповідає двом інтегруючим ланкам, мають вигляд:

$$
\begin{aligned}
& \frac{d x_{1}(t)}{d t}=x_{2}(t-\tau) ; \\
& \frac{d x_{2}(t)}{d t}=u(t) ; \quad\left(0 \leq t \leq t_{k}\right),
\end{aligned}
$$

де: $x_{1}(t), x_{2}(t)$ - змінні стану системи керування;

$\tau=$ const $>0$ - чисте часове (транспортне) запізнювання;

$u(t)$ - керування, яке обмежене за величиною умовою

$$
|u(t)| \leq 1, \quad\left(0 \leq t \leq t_{k}\right),
$$

$t_{k}$ - кінцевий момент часового інтервалу керування;

$$
x_{1}(0)=x_{1}^{0}, x_{2}(0)=x_{2}^{0} ; \quad x_{1}\left(t_{k}\right)=x_{2}\left(t_{k}\right)=0 \text { початкові і кінцеві умови. (3) }
$$

Для однозначного визначення руху системи на відрізку часу $t \in\left[0, t_{k}\right]$ необхідно задати допустиме керування $u(t),(0 \leq t \leq T)$ та початкову неперервну функцію $\varphi(t)$, яка визначена на відрізку $-\tau \leq t \leq 0$.

В результаті вектор-функція $\mathbf{x}(t)=\left\{x_{1}(t), x_{2}(t)\right\}$, яка задана на відрізку $-\tau \leq t \leq t_{k}$ і всюди неперервна на ньому, називається траєкторією системи (1), що відповідає допустимому керуванню $u(t)$ і заданій початковій функції $\varphi(t)(-\tau \leq t \leq 0)$, якщо фрункція $\mathbf{x}(t)$ на відрізку $0 \leq t \leq t_{k}$ задовольняе рівняння (1), а на відрізку $-\tau \leq t \leq 0$ збігається із функцією $\varphi(t)$.

Якщо крім забезпечення заданих межових умов (3) додатково вимагається, щоб у системі за $t \geq t_{k}$ забезпечувався заданий усталений рух вигляду

$$
x_{1}(t)=x_{2}(t)=0,
$$

то із-за наявного у системі чистого часового запізнювання цей режим досягається лише за умови

$$
x_{2}(t) \equiv 0, t_{k}-\tau \leq t \leq t_{k} .
$$

Послідовно використовуючи принцип максимуму і метод фразового простору $[1,2]$ вирішуемо дві задачі на оптимум витрат палива, перша з яких е так звана задача із колпроліснил критеріел, що враховуе швидкодію керування і витрати палива при нефіксованій тривалості 
перехідного процесу системи, а друга - тільки иисту витрату палива при заданій тривалості процесу керування.

Спочатку розглянемо першу оптимізаційну задачу.

Задача 1. Треба знайти оптимальне керування $u(t)$, яке переводить систему із заданого початкового стану $\mathbf{x}(0)=\mathbf{x}^{0}=\left\{x_{1}^{0}, x_{2}^{0}\right\}$ при початковій фрункції $\varphi(t) \triangleq x_{2}(t)(-\tau \leq t \leq 0)$ у кінцевий, нульовий стан $\mathbf{x}\left(t_{k}\right)=\left\{x_{1}\left(t_{k}\right), x_{2}\left(t_{k}\right)\right\}=0$ i забезпечує при цьому мінімум фрункціоналу

$$
J_{1}(u(t))=\int_{0}^{t_{k}}(k+|u(t)|) d t,
$$

де: $k>0$ - ваговий коефіцієнт, що враховує тривалість перехідного процесу у системі;

$t_{k}$ - заздалегідь не задано (не зафіксоване).

Згідно з принципом максимуму [2] гамільтоніан системи (1) для функціоналу (6) запишеться так:

$$
H[\mathbf{x}(t), u(t), \bar{\psi}(t)]=k+|u(t)|+\psi_{1}(t) x_{2}(t-\tau)+\psi_{2}(t) u(t) .
$$

Допоміжні змінні $\psi_{1}(t), \psi_{2}(t)$ є розв'язок канонічних рівнянь, що мають такий вигляд:

з яких маємо:

$$
\begin{aligned}
& \dot{\psi}_{1}(t)=0, \quad\left(0 \leq t \leq t_{k}\right) \\
& \dot{\psi}_{2}(t)=-\psi_{1}(t+\tau), \quad\left(0 \leq t \leq t_{k}-\tau\right) \\
& \dot{\psi}_{2}(t)=0, \quad\left(t_{k}-\tau \leq t \leq t_{k}\right)
\end{aligned}
$$

$$
\begin{aligned}
& \psi_{1}(t)=\psi_{1}^{0}=\text { const, }\left(0 \leq t \leq t_{k}\right) \\
& \psi_{2}(t)=-\psi_{1}^{0} t+\psi_{2}^{0},\left(0 \leq t \leq t_{k}-\tau\right) \\
& \psi_{2}(t)=-\psi_{1}^{0}\left(t_{k}-\tau\right)+\psi_{2}^{0}=\mathrm{const},\left(t_{k}-\tau \leq t \leq t_{k}\right)
\end{aligned}
$$

де $\psi_{1}^{0}, \psi_{2}^{0}$ - початкові умови для системи рівнянь (8).

Оптимальне керування $u^{*}(t)$, яке доставляє максимум гамільтоніану (7), визначається як

$$
u^{*}(t)= \begin{cases}0, & \text { якщо }\left|\psi_{2}(t)\right|<1 ; \\ -\operatorname{sign} \psi_{2}(t), & \text { якщо }\left|\psi_{2}(t)\right|>1 .\end{cases}
$$

за умови, що із розгляду виключаються вироджені керування вигляду

$$
\begin{aligned}
& 0 \leq u(t) \leq 1, \quad \text { якщо } \psi_{2}(t)=-1 ; \\
& -1 \leq u(t) \leq 0, \text { якщо } \psi_{2}(t)=1 .
\end{aligned}
$$

Графріки зміни значень функцій $\psi_{2}(t), u(t), \dot{x}_{1}(t), x_{2}(t)$ подано на рис. 1.

Співвідношення (10) визначають наступні оптимальні керуючі послідовності $\{0\},\{+1\},\{-1\},\{0,+1\},\{0,-1\},\{-1,0\},\{+1,0\},\{-1,0,+1\}$, $\{+1,0,-1\}$, із яких, своєю чергою відповідно до заданого кінцевого руху системи (1) можуть бути вилучені такі керуючі послідовності, як: $\{0\}$, 


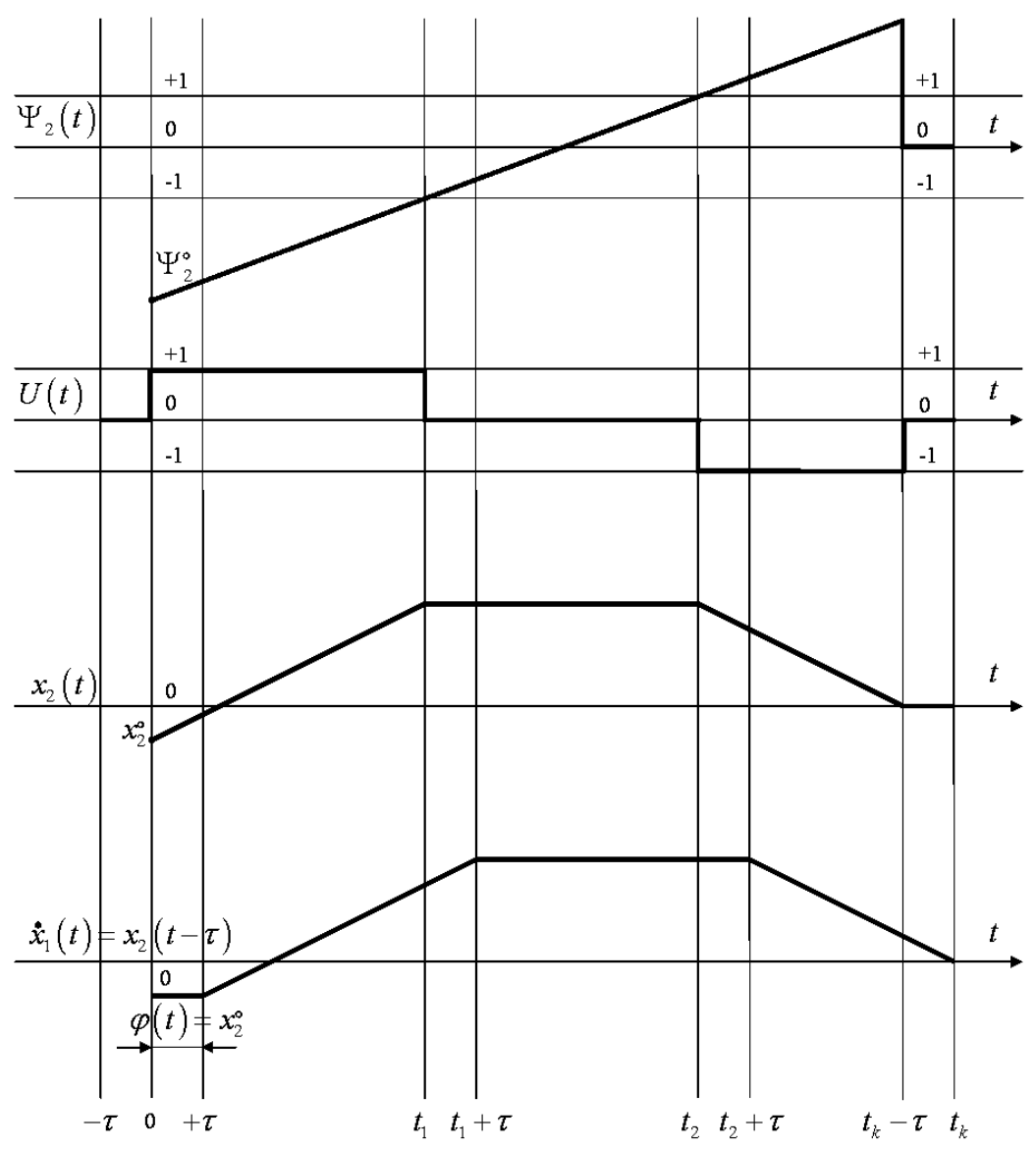

Рис. 1 - Графіки зміни значень функцій 
$\{+1,0\},\{-1,0\}$. Вибираючи за базові оптимальні керуючі послідовності загального виду $\left\{-u_{0}, 0, u_{0}\right\}$, де $u_{0}= \pm 1$, знаходимо у результаті інтегрування системи рівнянь (1) за межових умов (3) і “зшиваючи” фазові траєкторії із різних ділянок руху системи, отримаємо такі співвідношення між шуканими моментами перемикання оптимального керуючого впливу $u^{*}(t)$ :

$$
\begin{aligned}
& t_{3}-\left(t_{2}+t_{1}+\tau\right)=-u_{0} x_{2}^{0} ; \\
& t_{3}^{2}-\left(t_{2}+\tau\right)^{2}-\left(t_{1}+\tau\right)^{2}=2 u_{0} \tilde{x}_{1}^{0}-2 u_{0} x_{2}^{0} \tau-\tau^{2},
\end{aligned}
$$

де: $t_{1}, t_{2}, t_{3}$ - відповідно перший, другий і третій моменти перемикання оптимального керування $u^{*}(t)$;

$\tilde{x}_{1}^{0}=x_{1}^{0}+\int_{0}^{\tau} \varphi(t) d t-$ зміщена початкова умова завдяки ефекту запізнювання на початку першого інтервала руху системи.

Очевидо, що отримана система рівнянь не розв'язуеться відносно шуканих величин $t_{1}, t_{2}, t_{3}$, тому з метою отримання додаткового лінійно незалежного співвідношення між моментами $t_{i}(i=1,2,3)$ використовуеться умова стаціонарності гамільтоніана $H[\mathbf{x}(t), u(t), \bar{\psi}(t)]$ уздовж оптимальної траєкторії руху $\mathbf{x}^{*}(t)$, а саме у момент часу $t=t_{2}$.

$$
\left.H\left[\mathbf{x}^{*}(t), \mathbf{x}^{*}(t-\tau), \bar{\psi}^{*}(t), u^{*}(t)\right]\right|_{t=t_{2}}=0 .
$$

Звідси, з урахуванням того, що $u^{*}\left(t_{2}\right)=0$, отримуемо

$$
\left.H\right|_{t=t_{2}}=k+x_{2}\left(t_{2}-\tau\right) \psi_{1}^{0}=0
$$

і знаходимо

$$
\psi_{1}^{0}=\frac{k}{x_{2}\left(t_{2}-\tau\right)} .
$$

Використовуючи раніше отримані вирази (9) для допоміжних функцій $\psi_{1}(t), \psi_{2}(t)$, зв'язуемо невідому початкову умову $\psi_{1}^{0}$ з моментами часу $t_{1}$, $t_{2}$ таким чином. Маемо

$$
\begin{gathered}
\psi_{2}\left(t_{1}\right)=-\psi_{1}^{0} t_{1}+\psi_{2}^{0}=u_{0} \\
\psi_{2}\left(t_{2}\right)=-\psi_{1}^{0} t_{2}+\psi_{2}^{0}=-u_{0}
\end{gathered}
$$

і віднімаемо (16) із (17), отримуючи

$$
t_{2}-t_{1}=\frac{2 u_{0}}{\psi_{1}^{0}}
$$

і після підстановки (15) у (18) маємо

$$
t_{2}-t_{1}=\frac{1}{k}\left[2 u_{0} x_{2}(t-\tau)\right]
$$

Якщо тепер скористатися розв'язком системи диференціальних рівнянь (1) для координати $x_{2}(t-\tau)$, то маючи вираз 


$$
x_{2}\left(t_{2}-\tau\right)=x_{2}\left(t_{1}\right)=x_{2}^{0}-u_{0} t_{1},
$$

із (19) отримуємо шукане додаткове співвідношення між моментами $t_{2} \mathrm{i}$ $t_{1}$

$$
t_{2}=\frac{k+2}{k} t_{1}-\frac{2 u_{0} x_{2}^{0}}{k} .
$$

Розв'язуючи тепер вже сумісну систему рівнянь (12) і (21), знаходимо явні аналітичні вирази для моментів перемикання $t_{j}, j=1,2,3$ оптимального керування $u^{*}(t)$ :

$$
\begin{gathered}
t_{1}=u_{0} x_{2}^{0} \pm \sqrt{\frac{k}{k+2}\left(\frac{\left(x_{2}^{0}\right)^{2}}{2}+u_{0} \tilde{x}_{1}^{0}\right)}, \\
t_{2}=u_{0} x_{2}^{0} \pm \sqrt{\frac{k+2}{k}\left(\frac{\left(x_{2}^{0}\right)^{2}}{2}+u_{0} \tilde{x}_{1}^{0}\right)}, \\
t_{3}=t_{\kappa}=u_{0} x_{2}^{0} \pm 2(k+1) \sqrt{\frac{1}{k(k+2)}\left(\frac{\left(x_{2}^{0}\right)^{2}}{2}+u_{0} \tilde{x}_{1}^{0}\right)}+\tau .
\end{gathered}
$$

Вочевидь, співвідношення (22),(23) і (24) справджуються лише за умови, що $t_{j} \geq 0, j=1,2,3$ i $t_{2}-t_{1} \geq \tau$. Якщо значення величини $t_{1} \mathbf{e}$ від'ємне, це свідчить про відсутність першого інтервалу в оптимальній послідовності $\left\{-u_{0}, 0, u_{0}\right\}$, яка приймає такий скорочений вигляд: $\left\{0, u_{0}\right\}$, де $u_{0}= \pm 1$. Система алгебраїчних рівнянь відносно $t_{2}, t_{3}$ набувае вигляду

$$
\begin{aligned}
& t_{3}-\left(t_{2}+\tau\right)=-u_{0} x_{2}^{0}, \\
& t_{3}^{2}-\left(t_{2}+\tau\right)^{2}=2 u_{0} \tilde{x}_{1}^{0}-2 u_{0} x_{2}^{0} \tau,
\end{aligned}
$$

розв'язком якої буде

$$
\left.\begin{array}{l}
t_{2}=\frac{u_{0} x_{2}^{0}}{2}-\frac{\tilde{x}_{1}^{0}}{x_{2}^{0}} \\
t_{3}=t_{k}=-\frac{u_{0} x_{2}^{0}}{2}-\frac{\tilde{x}_{1}^{0}}{x_{2}^{0}}+\tau .
\end{array}\right\}
$$

Оскільки до кожного із виразів (22), (23), (24) і (26) для визначення моментів перемикання входить значення оптимального керування $u_{0}= \pm 1$ на першому, початковому інтервалі руху, то від правильного його вибору у значній мірі залежить вирішення поставленої задачі. Відомо, [1,6,7], що початкове керування $u_{0}$ залежить від межових умов $\mathbf{x}(0)=\mathbf{x}^{0}$ i $\mathbf{x}\left(t_{k}\right)$, але оскільки у даному випадку $\mathbf{x}\left(t_{k}\right)=0$, то досить визначити $u_{0}$ тільки як функцію $\mathrm{x}^{0}$, а саме

$$
u_{0}=\left\{\begin{array}{l}
\operatorname{sign} x_{1}^{0}, \text { якщо } x_{1}^{0} \neq 0, \\
\operatorname{sign} x_{2}^{0}, \text { якщо } x_{1}^{0}=0 .
\end{array}\right.
$$

Зауважимо, що якщо обидва значення для моменту $t_{1}$ згідно (22) $\mathrm{e}$ додатні, то як шукане слід вибирати більше з цих значень.

Тепер розглянемо вирішення другої задачі: 
Задача 2. Для системи вигляду (1) треба знайти оптимальне керування $u^{*}(t)$, яке переводить $\dddot{11}$ із початкового стану $\mathbf{x}(0)=\mathbf{x}^{0}$ у кінцевий нульовий стан $\mathbf{x}\left(t_{k}\right)=0$ за умови, що $x_{2}(t)=\varphi(t)(-\tau \leq t \leq 0)$, а функціонал якості процесу керування

$$
J_{2}(u(t))=\int_{0}^{t_{k}}|u(t)| d t
$$

досягав свого мінімального значення. Тут величина $t_{k}$ зазделегідь фіксована. Як і раніше, зберігаються умови (4) і (5) усталеного руху системи по завершенню перехідного процесу, які доповнюються умовою існування розв'язку даної задачі оптимального керування.

$$
t_{k} \geq t_{k}^{*}
$$

де $t_{k}^{*}$ - тривалість оптимального за швидкодією процесу керування для системи (1).

Використавши спочатку методику вирішення задач оптимальної швидкодії [6], знайдемо величину $t_{k}^{*}$, що визначає згідно з (29) існування розв'язку оптимізаційної задачі 2 . Ця величина дорівнює

$$
t_{k}^{*}=\tau+u_{0} x_{2}^{0} \pm \sqrt{\left(x_{2}^{0}\right)^{2} / 2+u_{0} \tilde{x}_{1}^{0}},
$$

де $\tilde{x}_{1}^{0}=x_{1}^{0}+\int_{0}^{\tau} \varphi(t) d t$ - зміщена завдяки початковій функції $\varphi(t)$ межова умова для координати $x_{1}(t)$, а допустимі значення для $t_{k}^{*}$ будуть тільки додатні.

В силу подібності процесів оптимального керування і рівного числа моментів перемикання для обох оптимізаційних задач для синтезу оптимальних програмних керувань при фіксованому $t_{k}$ досить у виразах (12) i (25) покласти третій кінцевий момент перемикання $t_{3}=t_{k}$

У підсумку з (12) при трьох інтерввалах оптимального керування $\left\{-u_{0}, 0, u_{0}\right\}$, де $u_{0}= \pm 1$, маемо:

$$
\begin{aligned}
& t_{1}=\frac{1}{2}\left[u_{0} x_{2}^{0}+t_{k}-\tau\right]-\frac{1}{2} \sqrt{\left(t_{k}+u_{0} x_{2}^{0}-\tau\right)^{2}-2\left(x_{2}^{0}\right)^{2}-4 u_{0} \tilde{x}_{1}^{0}} \\
& t_{2}=\frac{1}{2}\left[u_{0} x_{2}^{0}+t_{k}-\tau\right]+\frac{1}{2} \sqrt{\left(t_{k}+u_{0} x_{2}^{0}-\tau\right)^{2}-2\left(x_{2}^{0}\right)^{2}-4 u_{0} \tilde{x}_{1}^{0}}
\end{aligned}
$$

За наявності лише двох інтервалів оптимального керування $\left\{0, u_{0}\right\}$, коли вважаеться, що $t_{1}=0$, використовуеться тільки співвідношення (25), яке дає такі величини:

$$
\begin{aligned}
& t_{2}=t_{k}-\tau+u_{0} x_{2}^{0}, \\
& T_{k}=-\frac{\tilde{x}_{1}^{0}}{x_{2}^{0}}+\tau-\frac{u_{0} x_{2}^{0}}{2},
\end{aligned}
$$

де $T_{k}$ - тривалість оптимального за витратами палива двохінтервального процесу при початкових умовах (координатах) $\tilde{x}_{1}^{0}, x_{2}^{0}$ для критерія 
вигляду (28). Якщо $T_{k}>t_{k}$, то розв'язку оптимізаційної задачі 2 не існуе, а якщо $T_{k}<t_{k}$, то треба використовувати для керування трьохінтервальну послідовність $\left\{-u_{0}, 0, u_{0}\right\}$. I тільки за умови $T_{k}=t_{k}$ має місце відповідність початкових умов $\tilde{x}_{1}^{0}, x_{2}^{0}$ величині фіксованої тривалості $t_{k}$ оптимального за витратами палива перехідного процессу в системі (1).

Таким чином, на прикладі найпростішої системи другого порядку з транспортним запізнюванням вигляду (1) було показано, що програмне оптимальне за витратами оптимального керування залежить що від вигляду критерія оптимізації, так і від початкової функції $\varphi(t)(-\tau \leq t \leq 0)$ і межових умов.

\section{Література}

1. Атанс М., Фалб П. Оптимальное управление.-М.: Машиностроение, 1984.-764 c.

2. Понтрягин Л. С., Болтянский В. Г., Гамкрелидзе Р. В., Мищенко Е. В. Математическая теория оптимальных процессов.- М.: Наука, 1969.-364 c.

3. Табак Д., Куо Б. Оптимальное управление и математическое программирование.-М.: Наука, 1975.—270 с.

4. Игнатенко В. Н., Стенин А. А. О числе переключений в оптимальных по расходу топлива системах управления.// Адаптивные системы автоматического управления. Республиканский межведомственный сборник.-К.: Техніка, 1983, с.42-46.

5. Павлов А. А. Синтез релейных систем, оптимальных по быстродействию. М.: Наука, 1966.-250 с.

6. Олейников С. А., Зотов В. Г. Основы оптимального и экстремального управления.-Л.: Высшая школа.- 220 с.

7. Игнатенко В. Н., Стенин А. А., Сиз В. В. Оптимальное по расходу топлива управление системами второго порядка с запаздыванием. //Вестник КПИ, серия автоматики и электро-приборостроения.-К.: Техніка, 1973, с. 119-126.

8. Стенин А. А. Оптимальное по расходу топлива управление системами второго порядка с последействием при фиксированном времени перехода.// Вестник КПИ, серия технической кибернетики, 1.-К.: Техніка, 1977, с.11-13.

9. Антамонов Ю. Г. Автоматическое управление с применением вычислительных машин.-М.: Судпромгиз, 1962, с. 212.

10. Лернер А. Я. Принципы построения быстродействующих систем и регуляторов.-М.: Госэнергоиздат, 1961. с.250. 